\title{
Activation and localization of matrix metalloproteinase-2 and -9 in the skeletal muscle of the muscular dystrophy dog (CXMD,
} Kazuhiro Fukushima ${ }^{1}$, Akinori Nakamura*2, Hideho Ueda ${ }^{3}$, Katsutoshi Yuasa ${ }^{2}$, Kunihiro Yoshida ${ }^{1}$, Shin'ichi Takeda ${ }^{2}$ and Shu-ichi Ikeda ${ }^{1}$

\author{
Address: ${ }^{1}$ Third Department of Medicine (Neurology and Rheumatology), Shinshu University School of Medicine, Matsumoto 390-8621, Japan, \\ ${ }^{2}$ Department of Molecular Therapy, National Institute of Neuroscience, National Center of Neurology and Psychiatry (NCNP), Kodaira 187-8502, \\ Tokyo, Japan and ${ }^{3}$ Department of Anatomy and Cell Biology, School of Health Sciences, Shinshu University, Matsumoto 390-8621, Japan \\ Email: Kazuhiro Fukushima - fuku@hsp.md.shinshu-u.ac.jp; Akinori Nakamura* - anakamu@ncnp.go.jp; \\ Hideho Ueda - hueda@gipac.shinshu-u.ac.jp; Katsutoshi Yuasa - yuasa@ncnp.go.jp; Kunihiro Yoshida - kyoshida@hsp.md.shinshu-u.ac.jp; \\ Shin'ichi Takeda - takeda@ncnp.go.jp; Shu-ichi Ikeda - ikedasi@hsp.md.shinshu-u.ac.jp \\ * Corresponding author
}

Published: 28 June 2007

BMC Musculoskeletal Disorders 2007, 8:54 doi:10.1 186/I47/-2474-8-54
Received: 4 February 2007

Accepted: 28 June 2007

This article is available from: http://www.biomedcentral.com/147I-2474/8/54

(C) 2007 Fukushima et al; licensee BioMed Central Ltd.

This is an Open Access article distributed under the terms of the Creative Commons Attribution License (http://creativecommons.org/licenses/by/2.0), which permits unrestricted use, distribution, and reproduction in any medium, provided the original work is properly cited.

\begin{abstract}
Background: Matrix metalloproteinases (MMPs) are key regulatory molecules in the formation, remodeling and degradation of all extracellular matrix (ECM) components in both physiological and pathological processes in various tissues. The aim of this study was to examine the involvement of gelatinase MMP family members, MMP-2 and MMP-9, in dystrophin-deficient skeletal muscle. Towards this aim, we made use of the canine $X$-linked muscular dystrophy in Japan $\left(C X M D_{j}\right)$ model, a suitable animal model for Duchenne muscular dystrophy.

Methods: We used surgically biopsied tibialis cranialis muscles of normal male dogs $(n=3)$ and CXMD dogs $(n=3)$ at 4, 5 and 6 months of age. Muscle sections were analyzed by conventional morphological methods and in situ zymography to identify the localization of MMP-2 and MMP-9. MMP-2 and MMP-9 activity was examined by gelatin zymography and the levels of the respective mRNAs in addition to those of regulatory molecules, including MTI-MMP, TIMP-I, TIMP-2, and RECK, were analyzed by semiquantitative RT-PCR.

Results: In CXMD, skeletal muscle, multiple foci of both degenerating and regenerating muscle fibers were associated with gelatinolytic MMP activity derived from MMP-2 and/or MMP-9. In CXMD, muscle, MMP-9 immunoreactivity localized to degenerated fibers with inflammatory cells. Weak and disconnected immunoreactivity of basal lamina components was seen in MMP-9-immunoreactive necrotic fibers of CXMD muscle. Gelatinolytic MMP activity observed in the endomysium of groups of regenerating fibers in CXMD did not co-localize with MMP-9 immunoreactivity, suggesting that it was due to the presence of MMP-2. We observed increased activities of pro MMP-2, MMP-2 and pro MMP-9, and levels of the mRNAs encoding MMP-2, MMP-9 and the regulatory molecules, MTI-MMP, TIMP-I, TIMP-2, and RECK in the skeletal muscle of CXMD, dogs compared to the levels observed in normal controls.

Conclusion: MMP-2 and MMP-9 are likely involved in the pathology of dystrophin-deficient skeletal muscle. MMP-9 may be involved predominantly in the inflammatory process during muscle degeneration. In contrast, MMP-2, which was activated in the endomysium of groups of regenerating fibers, may be associated with ECM remodeling during muscle regeneration and fiber growth.
\end{abstract}




\section{Background}

Duchenne muscular dystrophy (DMD) is the most common lethal X-linked recessive disease, presenting with progressive muscular atrophy and weakness. DMD is caused by mutations in the DMD gene that encodes the cytoskeletal protein dystrophin. Dystrophin and the dystrophin-associated protein complex provide a crucial structural link between the extracellular matrix (ECM) and the intracellular actin cytoskeleton [1]. Dystrophin deficiency affects the sarcolemma-ECM interaction, resulting in sarcolemmal instability [2,3]. Histopathological hallmarks in DMD include degeneration, necrosis, and insufficient regeneration of muscle fibers, suggesting that constitutive ECM remodeling takes place in DMD skeletal muscles. Although the cycles of degeneration and regeneration of muscle fibers continues throughout postnatal development, regeneration gradually slows and the balance is eventually tipped in favor of degeneration in DMD [4].

ECM is a three-dimensional network of macromolecules, and transmits signals from cells to the ECM and vice versa, mediating cell adhesion, migration, proliferation, differentiation and survival [5]. Muscle fibers are embedded in connective tissue organized into three interconnected sheaths: (1) Epimysium is a collagenous tissue that surrounds whole muscle; (2) Perimysium is smaller bundles of collagen fibers extended inward from epimysium, separates muscle fibers into fascicles or bundles; (3) Endomysium encloses the individual muscle fibers, including basal lamina, capillaries, fine nerve branches, fibroblasts, and macrophages [6]. The basal lamina, which consists of ECM components such as type IV collagen, laminin, and proteoglycans, maintains the physiological integrity of the muscle fibers and has a role in muscle fiber repair after injury or excessive exercise [7]. In the last decade, matrix metalloproteinases (MMPs) have been shown to degrade all ECM components [8]. MMPs, a group of zinc-dependent endopeptidases, are thought to play a central role in the modulation of ECM functions [9]. MMPs are commonly induced by cytokine signals as inactive zymogens (pro-forms), that require processing of a prodomain by other MMPs or serine proteinases to attain full activity. Their activities are inhibited by endogenous MMP inhibitors (tissue inhibitors of metalloproteinases; TIMPs-1, -2, -3 , and -4) [10,11]. Membranous type metalloproteinases (MT-MMPs) have recently been discovered as a subgroup of membrane-anchored metalloproteinases. Membranous type metalloproteinase-1 (MT1-MMP) is associated with pro matrix metalloproteinase type 2 (pro MMP-2) and TIMP-2 to form a trimolecular complex, that activates pro MMP-2. [12-16]. Reversion-inducing-cysteine-rich protein with Kazal Motifs (RECK) is a new class of membrane-anchored inhibitor of MMP-2, matrix metalloproteinase type 9 (MMP-9), and MT1-MMP [17]. RECK has been described as a tumor and metastasis suppressor, as well as an angiogenesis suppressor and regulator of ECM integrity $[18,19]$. MMP activity contributes to a variety of physiological processes, such as embryonic development, organ morphogenesis, cell migration, apoptosis, angiogenesis, cartilage remodeling, bone growth, and wound healing $[8,10,20]$. On the other hand, loss of the exquisite regulation of MMPs leads to extensive ECM degradation, resulting in various diseases such as tumor progression or metastasis, cerebrovascular diseases, cardiovascular diseases, rheumatoid arthritis, and lung diseases. Therefore, MMP inhibitors can be useful prospective agents for the prevention and treatment of these diseases [21-27].

With respect to muscular disorders, particular attention has been paid to a subgroup of MMPs termed 'gelatinases,' comprising MMP-2 (also called gelatinase $\mathrm{A}$, or $72-\mathrm{kDa}$ type IV collagenase) and MMP-9 (also called gelatinase $\mathrm{B}$, or $92-\mathrm{kDa}$ type $\mathrm{V}$ collagenase). These enzymes contain three repeats of a gelatin-binding type II fibronectin domain inserted into their catalytic domain [28]. Besides gelatin, they degrade various ECM components including denatured type I, II, and III collagen, native IV and V collagen, laminin, elastin, proteoglycan, and fibronectin $[28,29]$. In some inflammatory myopathies, MMP-9 is expressed primarily by invading $\mathrm{T}$ lymphocytes, and is implicated in the pathogenesis [30-32]. MMP-2 is up-regulated in DMD skeletal muscle, and is expressed by mesenchymal fibroblastic cells [33]. Up-regulation of MMP-2 and MMP-9 has also been observed in skeletal muscle of dystrophin-deficient $m d x$ mice [34,35], an animal model of DMD. Moreover, it has been reported that MMP-2 and MMP-9 are able to process beta-dystroglycan and disrupt the link between the ECM and the cell membrane via the dystroglycan complex in the skeletal muscle from DMD and sarcoglycanopathy patients [36-38].

We hypothesized that MMP-2 and/or MMP-9 might also play an important role in the pathogenesis of muscular dystrophies, involving ECM remodeling during the cycle of muscle fiber degeneration and regeneration. We evaluated the expression, activation, and immunolocalization of MMP-2 and MMP-9, as well as of regulatory molecules MT1-MMP, TIMP-1, TIMP-2 and RECK, in the dystrophindeficient skeletal muscle of the canine X-linked muscular dystrophy in Japan $\left(\mathrm{CXMD}_{\mathrm{J}}\right)$ model of $\mathrm{DMD}$, which shows more prominent skeletal muscle involvement than $m d x$ mice [39].

\section{Methods \\ Animals}

$\mathrm{CXMD}_{\text {J }}$ dogs were established by insemination of beagles with the sperm of golden retriever muscular dystrophy (GRMD) dogs [40]. CXMD J dogs lack dystrophin in the sarcolemma of skeletal muscles and exhibit typical dys- 
trophic phenotypes, as observed in DMD and GRMD $[39,41]$. We studied three normal male dogs (Beagle) at 4 , 5 and 6 months of age and three age-matched $\mathrm{CXMD}_{\text {J }}$ dogs. Each of the CXMD dogs presented with typical clinical signs of muscular dystrophy: progressive muscular atrophy and weakness, and elevated serum creatine kinase (CK) levels. The tibialis cranialis muscles of control and $\mathrm{CXMD}_{\mathrm{J}}$ dogs were obtained by surgical biopsy at the General Animal Research Facility of the National Institute of Neuroscience at the National Center of Neurology and Psychiatry (NCNP, Tokyo, Japan). The samples were rapidly frozen in isopentane cooled by liquid nitrogen. The treating and care of the dogs, and all experimental procedures, were approved by the Ethics Committee for the Treatment of Laboratory Middle-Sized Animal of the National Institute of Neuroscience, National Center of Neurology and Psychiatry (NCNP) (Tokyo, Japan). All experiments were performed with appropriate measures taken for preventing unnecessary pain.

\section{Film in situ zymography}

To detect the localization of gelatinolytic MMP activity in skeletal muscle tissues, we performed film in situ zymography (FIZ) as previously described [42-48]. $6 \mu \mathrm{m}$-thick cryosections from frozen samples were placed on a polyethylene terephthalate base film coated with $7 \mu \mathrm{m}$ thickness cross-linked gelatin with (FIZ-GI, Wako Pure Chemical, Osaka, Japan) or without (FIZ-GN, Wako Pure Chemical) 1,10-phenanthroline (inhibitor of MMPs, but not of other proteinases such as trypsin). The films with sections were incubated in a moist chamber for 6 hours at $37^{\circ} \mathrm{C}$. Then the films were stained with Biebrich Scarlet for $4 \mathrm{~min}$ and rinsed for $10 \mathrm{~min}$ at room temperature. The degraded gelatin was not stained with Biebrich Scarlet, and areas of gelatinolytic activity were visualized as white or weakly red areas on the red background. Gelatinolysis observed on FIZ-GN films, but not on FIZ-GI films, indicated the presence of MMP activity. Gelatinolysis seen on both FIZ-GN and FIZ-GI films indicated the activity of proteases other than MMPs (such as trypsin). The application of gelatin as substrate for in situ zymography has the advantage that MMP-2 and/or MMP-9 have a high affinity for this substrate [49].

\section{Histopathology and immunohistochemistry}

Serial $8 \mu \mathrm{m}$-thick cryosections of frozen muscle were prepared and stained with hematoxylin and eosin (HE). The sections were blocked with $10 \%$ goat serum (Cedarlane Laboratories, Burlington, Canada) in PBS for 15 min and incubated at $4{ }^{\circ} \mathrm{C}$ overnight with primary antibodies, followed by secondary staining. Stained specimens were mounted in Vectashield with DAPI (4', 6-diamidino-2phenylindole, dihydrochloride) (Vector Laboratories, Burlingame, CA) for nuclear counterstaining and photographed using a fluorescence microscope BX51 (OLYM-
PUS, Tokyo, Japan) equipped with an air-cooled CCD camera VB-7010 (KEYENCE, Oosaka, Japan) and VBViewer software (KEYENCE). Primary antibodies were used as follows: rabbit anti-MMP-2 antibody (AB809, Chemicon International, Temecula, CA), rabbit antiMMP-9 antibody (AB19047, Chemicon International), mouse anti-CD11b antibody (MCA1777S, Serotec, Oxford, UK), mouse-anti myosin developmental type heavy chain (NCL-MHCd, Novocastra, Newcastle Upon Tyne, UK), mouse anti-laminin B2 antibody (MAB1920, Chemicon International), rat anti-heparan sulfate proteoglycan, perlecan antibody (MAB1948, Chemicon International), rabbit anti-TIMP-1 antibody (sc-5538, Santa Cruz Biotechnology, Santa Cruz, CA), rabbit anti-TIMP-2 antibody (sc-5539, Santa Cruz Biotechnology), goat antiMT1-MMP antibody (sc-12367, Santa Cruz Biotechnology), and goat anti-RECK antibody (sc-8689, Santa Cruz Biotechnology). CD11b is a leukocyte-associated antigen expressed on monocytes, macrophages, and granulocytes [50]. Myosin developmental type heavy chain (MHCd) is a myosin heavy chain isoform, present during muscle fiber regeneration, in the embryonic and neonatal periods [51].

\section{Gelatin zymography}

Frozen skeletal muscles were homogenized in an extraction buffer (62.5 mM Tris-HCl $\mathrm{pH} 6.8,2 \%$ sodium dodecyl sulfate (SDS) $10 \%$ glycerol) and total protein content was assessed by the Bio-Rad DC Assay kit (BioRad Laboratories, Hercules, CA). $100 \mu \mathrm{g}$ of each extract dissolved in a loading buffer provided by the manufacture were electrophoresed through a gelatin-containing SDS polyacrylamide gel provided as part of the gelatin zymography kit (Gelatin Zymography kit, Yagai, Tokyo, Japan). The gel was washed with washing buffer and then incubated for 36 hours at $37^{\circ} \mathrm{C}$ in reaction buffer, provided by the manufacture. The gels were stained in Coomasie Brilliant Blue and destained with destain solution (Bio-Rad Laboratories). Gelatinolytic activity was identified as clear bands on a blue background. Gelatin zymography detects the activity of both active and pro-form gelatinolytic MMPs. This is because exposure to SDS during gel electrophoresis causes activation of the pro-form MMPs without proteolytic cleavage of the prodomain [52]. Quantitative results of the assays were obtained by densitometry using Image v1.34s (National Institutes of Health; NIH, Bethesda, MD).

\section{RNA isolation and reverse transcription}

Total RNA was isolated from the skeletal muscles using the RNeasy fibrous tissue mini kit (QIAGEN, Hilden, Germany) and RNA quality was spectrophotometrically assessed. Reverse transcription to CDNA was performed in buffered solution containing dATP, dCTP, dGTP, dTTP, FPLCpure murine reverse transcriptase, RNA guard (por- 
cine), RNase/DNase-free bovine serum albumin, and NotI-d (T) 18 primer [5'd(AACTGGAAGAATTCGCGGCCGCAGGAAT18)-3']

according to the manufacturer's instructions, using the Ready-To-Go T-Primed First Strand Reaction Kit (Pharmacia Biotech, Brussels, Belgium).

\section{Semi-quantitative RT-PCR}

The PCR amplifications were carried out in the presence of $1.5 \mathrm{mM} \mathrm{MgCl} 2$ by using standard PCR buffer, $0.2 \mathrm{mM}$ dNTPs, $0.4 \mathrm{mM}$ of each forward and reverse primer, $1 \mu \mathrm{l}$ of RT products, and 0.1 units Taq DNA polymerase in a total volume of $25 \mu \mathrm{l}$. We designed PCR primers based on the previously published cDNAs of the canine gene sequences for MMP-2, MMP-9, MT1-MMP, TIMP-1, TIMP2, and RECK (Table 1). 18S ribosomal RNA was used as an internal control in the semi-quantitative RT-PCR experiments. A 324 bp fragment of 18 s was amplified using QuantumRNA $^{\mathrm{TM}}$ Classic II 18S Internal Standard (Ambion, Austin, TX). 18S rRNA primers were mixed with competimers at an optimized ratio of 5:5 so that the signal for $18 \mathrm{~S}$ rRNA was attenuated to the level of messages of targets by modulating the efficiency of amplification of the 18S PCR product. The PCR conditions were: initial denaturation for $1 \mathrm{~min}$ at $94^{\circ} \mathrm{C}$; followed by 30 cycles (for MT1-MMP, TIMP-1, and TIMP-2), or 32 cycles (for MMP9 and RECK) of $94^{\circ} \mathrm{C}$ for $30 \mathrm{sec}, 60^{\circ} \mathrm{C}$ for $30 \mathrm{sec}$ and $72^{\circ} \mathrm{C}$ for $30 \mathrm{sec}$; and a final extension of $10 \mathrm{~min}$ at $72^{\circ} \mathrm{C}$. The number of cycles was determined experimentally so that semi-quantitative comparison could be made during the exponential phase of the amplification process for each target and 18S rRNA gene. The relative expression level of each target gene was calculated by normalization against the 18s rRNA level. The PCR products were electrophoresed through a $2.5 \%$ agarose gel stained with ethidium bromide. The gel images were obtained using the GENE FLASH syngene bio imaging (TopoGEN, Port Orange, FL), and the densities of the products were quantified using ImageJ v1.34s (NIH). All assays were conducted in triplicate.

\section{Statistical analysis}

Quantitative data were compared in both groups by Mann-Whitney's U test. The data are presented as mean \pm SEM. $P<0.05$ was considered to indicate statistical significance.

\section{Results}

\section{Histopathology and in situ zymography}

$\mathrm{CXMD}_{\text {I }}$ muscles showed typical histopathological hallmarks of degeneration and regeneration. Multiple foci of both degenerating and regenerating muscle fibers were observed simultaneously in the same section (Fig. 1C). We examined the localization of gelatinolytic activity in the skeletal muscle of control and $\mathrm{CXMD}_{\mathrm{J}}$ dogs. In con- trols, low gelatinolytic activity was detected in the endomysium (Fig. 1A,B). In contrast, strong activity was detected in the endomysial space with infiltrating inflammatory cells in $\mathrm{CXMD}_{\mathrm{J}}$ muscles (Fig. 1D,E). Moreover, the endomysium of groups of regenerating fibers showed prominent gelatinolytic activity in $\mathrm{CXMD}_{\mathrm{J}}$ muscles (Fig. $1 F, G)$.

We next examined the fibers characterized by prominent gelatinolytic activity using immunohistochemistry. Strong gelatinase activity was detected in the endomysium not only of fibers with infiltration of $\mathrm{CD} 11 \mathrm{~b}$ positive cells (Fig. 2A,B,C), but also of MHCd-positive, small caliber, centronuclear fibers (Fig. 2E,F,G), which represent degenerating and regenerating fibers, respectively. Gelatinolytic activity was attenuated by the MMP inhibitor, 1,10-phenanthrolone (Fig. 2D,H), indicating that it was specifically derived from MMPs, and not from other proteases.

\section{Immunohistochemistry of MMP-9}

In $\mathrm{CXMD}_{\text {J }}$ muscle, MMP-9 immunoreactivity was detected in the necrotic fibers with inflammatory cell invasion and their endomysial space. MMP-9 immunoreactivity was colocalized with that of CD11b (Fig. 3G-J). Some MMP-9positive fibers had degenerated and showed a weak and discontinuous immunoreactivity pattern of basal lamina components, perlecan (Fig. 3O-R) and laminin B2 (Fig. $3 \mathrm{~S}-\mathrm{V}$ ). On the other hand, regenerating fibers (MHCdpositive fibers) in $\mathrm{CXMD}_{\mathrm{J}}$ muscle did not show MMP-9 immunoreactivity (Fig. 3K-N). Control muscle did not show a significant immunoreactivity for MMP-9, CD11b and MHCd (Fig. 3B,C and 3D, respectively), and revealed a normal immunoreactivity of perlecan and laminin B2 (Fig. 3E and 3F, respectively). Each immunohistochemistry of MMP-2, MT1-MMP, TIMP-1, TIMP-2, or RECK failed because of poor immunoreactivity of each antibody to the canine isoforms.

\section{Gelatin zymography}

We next evaluated the activity of each of the gelatinolytic enzymes (MMP-2, pro MMP-2 and pro MMP-9) in the muscle of normal and $\mathrm{CXMD}_{\text {I }}$ dogs by gelatin zymography analysis. This analysis detected gelatinolytic enzyme activity associated with proteins of molecular weights corresponding to $74 \mathrm{kDa}, 64 \mathrm{kDa}$ and $92 \mathrm{kDa}$, which indicate the presence of pro MMP-2, and the active forms of MMP2 and pro MMP-9, respectively. The activities of the three enzymes, particularly pro MMP-9, were increased in $\mathrm{CXMD}_{\mathrm{J}}$ muscle compared to control samples. MMP-9 was only detected as the pro-form (Fig. 4A). A semi-quantitative analysis showed a significant difference in each MMP activity between $\mathrm{CXMD}_{\mathrm{J}}$ and normal dog muscle (Fig. 4B). 
Table I: Primer sets used for PCR

\section{MMP-2}

(XM 535300)

MMP-9

(AF 001003219)

MTI-MMP

(AF 097638)

TIMP-I

(NM 001003182 )

TIMP-2

(AF 095638)

RECK

(NM 001002985)
Forward 5'-TGCAAGGCAGTGGTCATAGCT-3' (1724-1744)

Reverse 5'-AGCCAGTCGGATTTGATGCT-3' (1829-1810)

Forward 5'-CССTGCCACTTCCCCTTCACC-3' (707-727)

Reverse 5'-GAGCGGCCCTCGAAGGTGAAC-3' (895-915)

Forward 5'-AGGAGACAAGCACTGGGTGTT-3' (38-58)

Reverse 5'-AGGGATTCCTTCCCAGACCTT-3' (249-269)

Forward 5'-CCGACTTAAACCGGCGTTAT-3' (20I-220)

Reverse 5'-GATCAACACCTGCAGTTTCG-3' (40I-420)

Forward 5'-CAAAGCGGTCAGTGTGAAGG-3' (I-20)

Reverse 5'-CTTTGTGACTTCATCGTGCC-3' (236-255)

Forward 5'-TGCCCCGAAACAATGGTTGA-3' (246-265)

Reverse 5'-TCTCGGCAGTTTGTGTGATGG-3' (494-5।4)


CXMD J
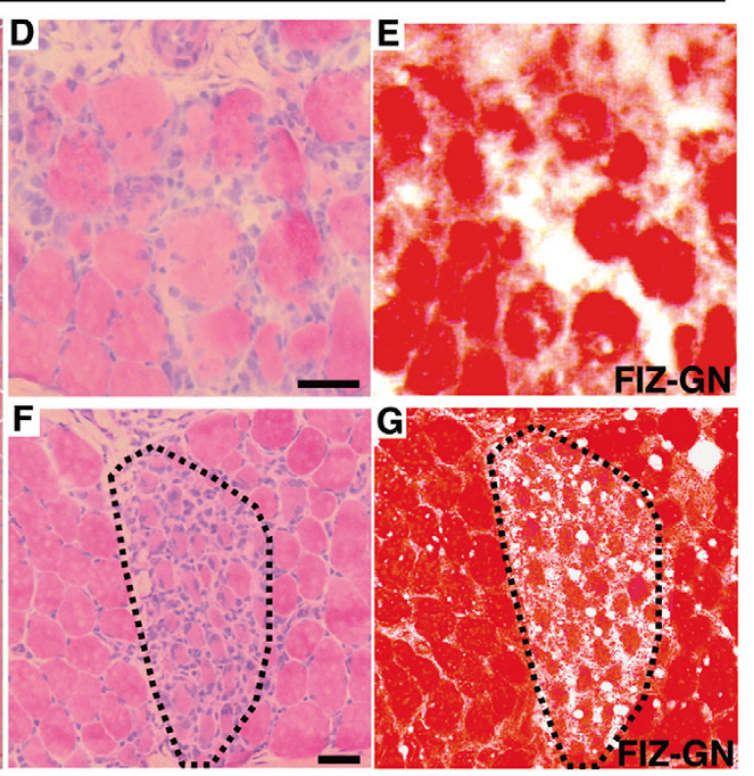

Figure I

Film in situ zymography (FIZ-GN) of skeletal muscle in CXMD, dogs. Hematoxylin and eosin (H\&E) staining (A, C, D, and $F)$ and film in situ zymography (FIZ-GN) (B, E, and $G)$ of the tibialis cranialis muscle in a normal dog $(A, B)$ and a CXMD, $\operatorname{dog}(C-G)$. D and $E$ (magnified views of $C-a)$ : a representative area of massive necrotic fibers with inflammatory infiltrate. $F$ and $\mathrm{G}$ (magnified views of $\mathrm{C}-\mathrm{b}$ ): a representative area of a group of regenerating fibers. Gelatinolytic activities were visualized as white or weakly red areas on the red background. Bars, $100 \mu \mathrm{m}$. 


\section{CXMD $_{J}$}
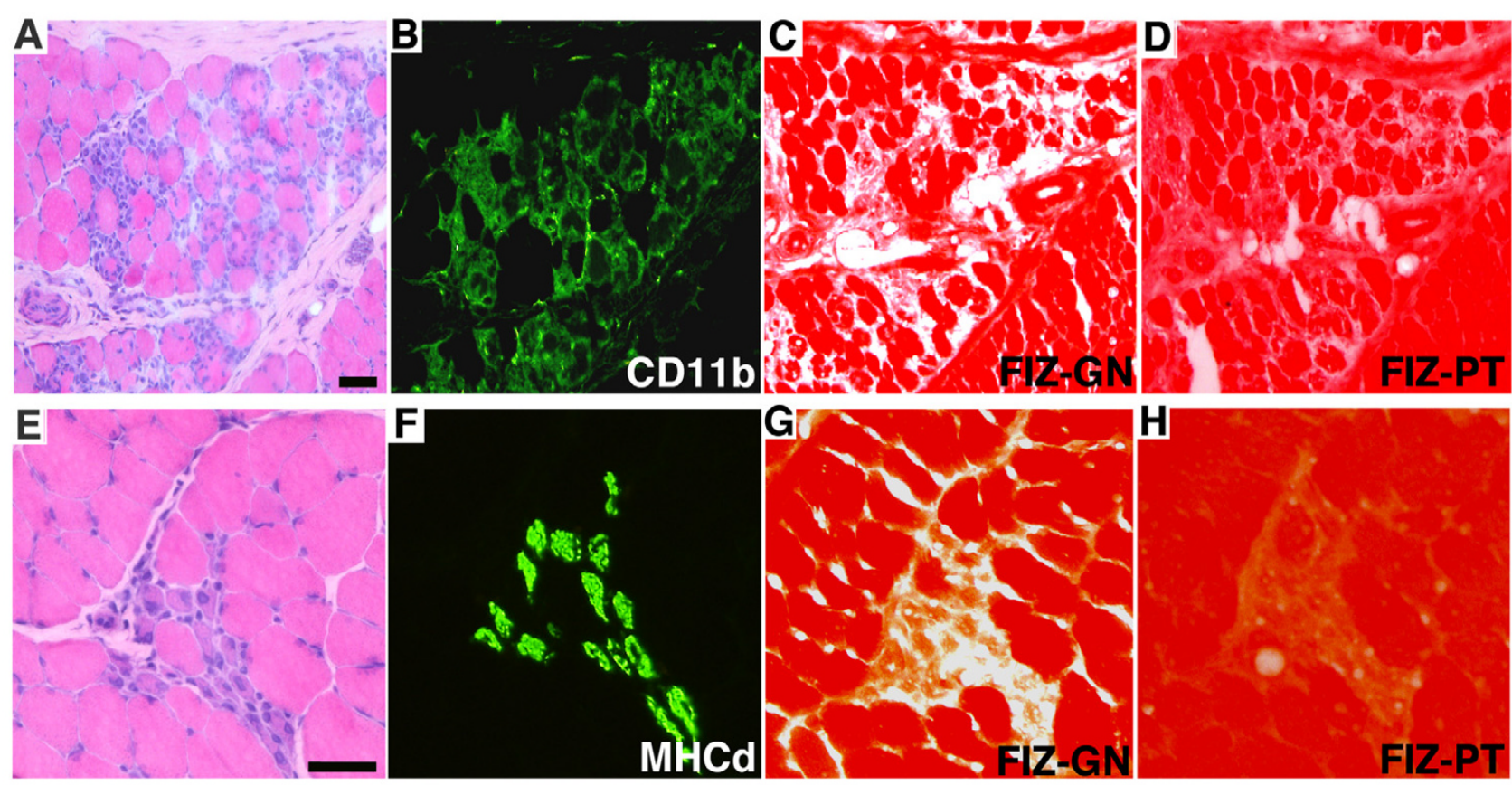

Figure 2

Immunohistochemical analysis of CDI Ib or MHCd expression, and film in situ zymography in the presence and absence of an MMP inhibitor (FIZ-PT) in the skeletal muscle of CXMD, dogs. A-D: serial sections of CXMD, muscle characterized by extensive necrosis and an invading inflammatory infiltrate; $\mathrm{E}-\mathrm{H}$ : serial sections of groups of regenerating fibers in CXMD, muscle. A and B: H\&E staining; $B$ and F: immunohistochemical analysis of CDI Ib; $\mathrm{C}$ and G: FIZ-GN; D and H: FIZ in the presence of an MMP inhibitor (I,I0-phenanthrolone) (FIZ-PT). Gelatinolytic activity co-localized with CDI Ib and MHCd, immunoreactivity and was attenuated by adding I,I0-phenanthrolone to the FIZ assay system. Bars, $50 \mu \mathrm{m}$.

\section{Semi-quantitative RT-PCR}

We next analyzed each gene expression of the gelatinolytic enzymes or the associated regulatory molecules in control and $\mathrm{CXMD}_{\mathrm{J}}$ dog muscle. A semi-quantitative analysis of the mRNA level encoding MMP-2, MMP-9, MT1-MMP, TIMP-1, TIMP-2, and RECK revealed that they were significantly increased in $\mathrm{CXMD}_{\mathrm{I}}$ muscle compared to the levels in control muscle (Fig. 5).

\section{Discussion}

Our data suggest that ECM remodeling mediated by MMP-2 and MMP-9 is a key process in skeletal muscle fiber degeneration and regeneration in $\mathrm{CXMD}_{\mathrm{J}}$ dogs. An FIZ assay revealed multiple foci of both degenerating and regenerating muscle fibers associated with gelatinolytic activity that was attenuated by exposure of the tissue to an MMP inhibitor, 1,10-phenanthrolone, indicating the presence of the activity of the gelatinolytic subgroup MMPs, MMP-2 and MMP-9. We also observed increased MMP-2 and MMP-9 activity and expression using gelatin zymography and by measuring the corresponding
mRNAs, respectively. In addition, we observed increased expression of the regulatory molecules, TIMP-1, TIMP-2, RECK, and MT1-MMP. Overall proteolytic activity is not easily predicted by RT-PCR findings on MMPs and their regulators, but we performed FIZ to know total gelatinase activities in situ. Our results showed that two proteases, MMP-2 and/or MMP-9 were highly activated in certain areas, although the data was not quantitative.

We showed that MMP-9 was localized to the endomysial space of inflammation in $\mathrm{CXMD}_{\mathrm{J}}$ muscle. MMP-9 seems to be derived from infiltrating granulocytes, monocytes or macrophages, since MMP-9 and CD11b immunoreactivity appear to co-localize. Degenerating fibers associated with MMP-9 immunoreactivity exhibited weak and disconnected expression of basal lamina components, laminin B2 and perlecan. These results suggest that MMP-9 may promote the degradation of the basal lamina in necrotic fibers in $\mathrm{CXMD}_{\mathrm{J}}$ muscle, followed by inflammatory cell invasion. In cardiotoxin-injected mice, MMP-9 was induced within $24 \mathrm{~h}$ of injection into skeletal muscle 


\section{Control}
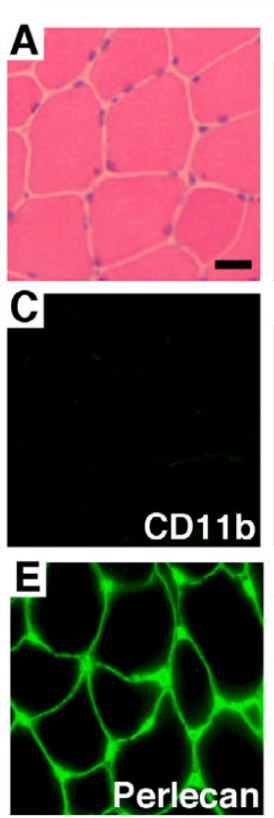
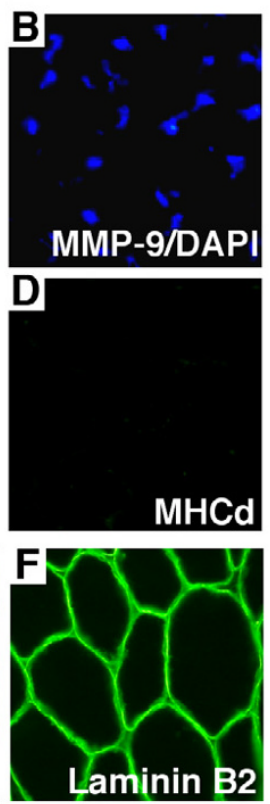


$\mathrm{CXMD}$


\section{Figure 3}

Co-immunolocalization of MMP-9, Perlecan, and laminin B2 in the skeletal muscle of CXMD, dogs. H\&E staining (A, G, K, O and S). Immunohistochemical analysis of MMP-9 (red), with nuclear counterstain using DAPI (blue) (B, H, L, P and T), CDI Ib (green, C and I), MHCd (green, D and M), Perlecan (green, E and Q), laminin B2 (green, F and $U$ ). Merged images of MMP-9 immunoreactivity with that of CDI Ib $(J)$, MHCd (N), Perlecan (R) and laminin B2 (V) in normal control (A-F) and in a CXMD, muscle (G-V). MMP-9 was detected in necrotic fibers associated with invading inflammatory cells and co-localized with $\mathrm{CDI}$ Ib (G-J). The endomysium of surrounding MHCd-positive regenerating fibers showed no MMP-9 immunoreactivity (K-M). A fraction of the MMP-9-positive fibers had degenerated and showed a weak and discontinuous pattern of immunostaining of both perlecan (O-R) and laminin B2 (S-V). Bars, $25 \mu \mathrm{m}$.

and was associated with inflammatory cell invasion, and MMP-9 mRNA was localized to invading polymorphonuclear cells and macrophages [34]. In human inflammatory myopathies, it has been reported that MMP-9 is produced primarily by invading $\mathrm{T}$ lymphocytes [30-32]. It is conceivable that MMP-9 may also contribute to elimination of necrotic fibers, so as to make room for muscle regeneration. MMP-9 is reported to be associated with muscle satellite cells; an adult muscle precursor and candidate muscle stem cell, and cultured human muscle satellite cells treated with phorbol ester [53]. MMP-9 mRNA was expressed in putative activated satellite cells in injured mouse muscle [34]. Taken together, these data suggest that MMP-9 might be associated not only with ECM deg- radation during inflammation, but also during the initiation of muscle regeneration. In our experiments, we detected only the latent form of MMP-9 (pro MMP-9) in the gelatin zymography. Regarding MMP-9, it has been reported that MMP-9 is not always detected in many tissues in vivo, although pro MMP-9 is converted to MMP-9 by various protease such as MMP-1, MMP-2, MMP-3 or plasminogen activator in vitro [54]. In addition, MMP-9 activation locally occurs in a pericellular environment by inflammatory response, leaving much of the secreted MMP in its pro-form [55].

Our data indicated that MMP-2 might be activated in the endomysium of regenerating fibers in $\mathrm{CXMD}_{\mathrm{J}}$ muscle. The 
A

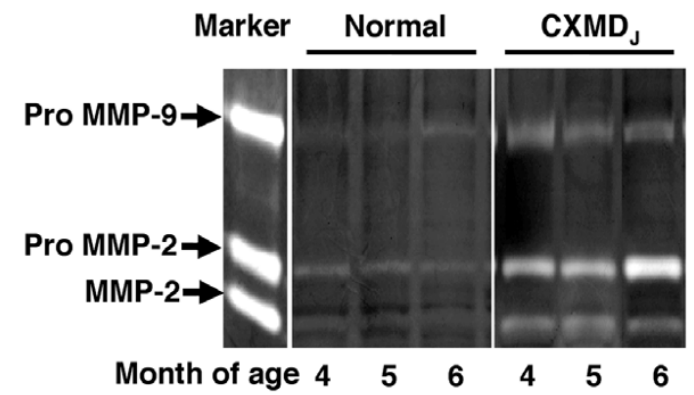

B

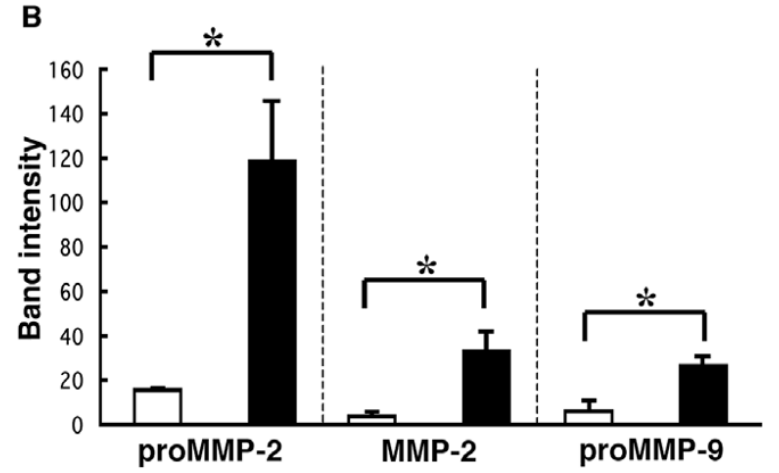

Figure 4

Gelatinolytic activities assessed by zymography in the muscle of normal and CXMD dogs. A. Equal amounts of protein $(100 \mu \mathrm{g})$ extracted from tibialis cranialis muscle was loaded onto a gelatin-containing SDS polyacrylamide gel. Gelatinolytic activity was identified as clear bands on a background. The activities of MMP-2, pro MMP-2 and pro MMP-9 were increased in the muscles of CXMD, dogs ( $\mathrm{n}$ $=3$ ) compared with those in the muscle of normal control dogs $(n=3)$. B. Semi-quantitative analysis of the activities of pro MMP-2, MMP-2 and pro MMP-9 in control (open bar, $n=$

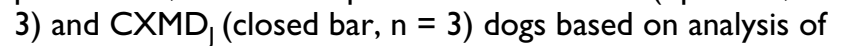
the band intensity associated with each activity. Bar: mean \pm SEM; $* p<0.01$.

endomysium of regenerating fibers were associated with gelatinolytic MMP activity, but were not associated with MMP-9 immunoreactivity. These results suggest that MMP-2, but not MMP-9, is activated in the vicinity of regenerating fibers. In a previous report, MMP-2 transcripts were predominantly found in the areas of fiber degeneration and ECM regeneration, and were localized to mesenchymal fibroblasts in DMD skeletal muscle [33]. During muscle degeneration and regeneration induced by cardiotoxin injection, MMP-2 activity seems to be increased concomitantly with the transition from the regeneration phases characterized by the appearance of young myotubes to maturation of the myotubes into multinucleated myofibers $[34,56]$. We therefore, assume that MMP-2 may take part in ECM remodeling occurring in the endomysium of regenerating fibers, as they grow into mature fibers. Additionally, there are some reports indicating that MMP-2 is involved in earlier phases of muscle regeneration. In the mouse myoblastic $\mathrm{C} 2 \mathrm{C} 12$ cell line, MMP-2 and MT1-MMP promote myoblast fusion [57], and MMP-2 could degrade the basal lamina components during myoblast fusion [40].

TIMPs, endogenous tissue inhibitors of MMPs, have been considered to be involved in the activities of MMPs. The expression of TIMPs has been explored in some diseased skeletal muscle, but their results were not conclusive. One report mentioned that expression of TIMP-1 and TIMP-2 mRNA levels were not different between inflammatory myopathies/inclusion body myositis and muscular dystrophy [32]. While, it has been also reported that both TIMP-1 and TIMP-2 mRNA levels in DMD muscle were increased than those in normal or other pathological controls, resulting in the promotion of muscle fibrosis [33]. Therefore, it is valuable to compare expression of TIMPs in dystrophin-deficiency and those in experimental models for muscle degeneration-regeneration. In our study, we presented up-regulation of TIMPs in the same skeletal muscle from $\mathrm{CXMD}_{\text {J }}$ at 4 to 6 months of age, where both necrosis and regeneration was active and existed at the same time. In injured mouse skeletal muscle by cardiotoxin injection, the increase of TIMP-1 mRNA levels was noticed a little later than the peak of MMP-9 mRNA, whereas TIMP-2 mRNA levels were found corresponding to the increase in MMP-2 mRNA (Fukushima et al., unpublished observations). We, therefore, suppose that MMPs and TIMPs upregulation may depend on the stage of muscle pathology; muscle necrosis or muscle regeneration, although cardiotoxin injection into canine skeletal muscle would allow us to directly compare muscle regeneration process and pathology of muscular dystrophy.

\section{Conclusion}

Based on our study, MMP-9 may be predominantly involved in the inflammatory process during muscle degeneration, while MMP-2 may be associated with ECM remodeling during muscle regeneration and fiber growth. To further elucidate the specific functions of each MMP and TIMP, canine muscle injury model by injection of a mytotoxic agent would be largely informative and therefore indispensable.

\section{Competing interests}

The author(s) declare that they have no competing interests.

\section{Authors' contributions}

KF carried out the molecular and pathological examination, and drafted the manuscript. AN participated in the design of the study and drafted the manuscript. HU per- 


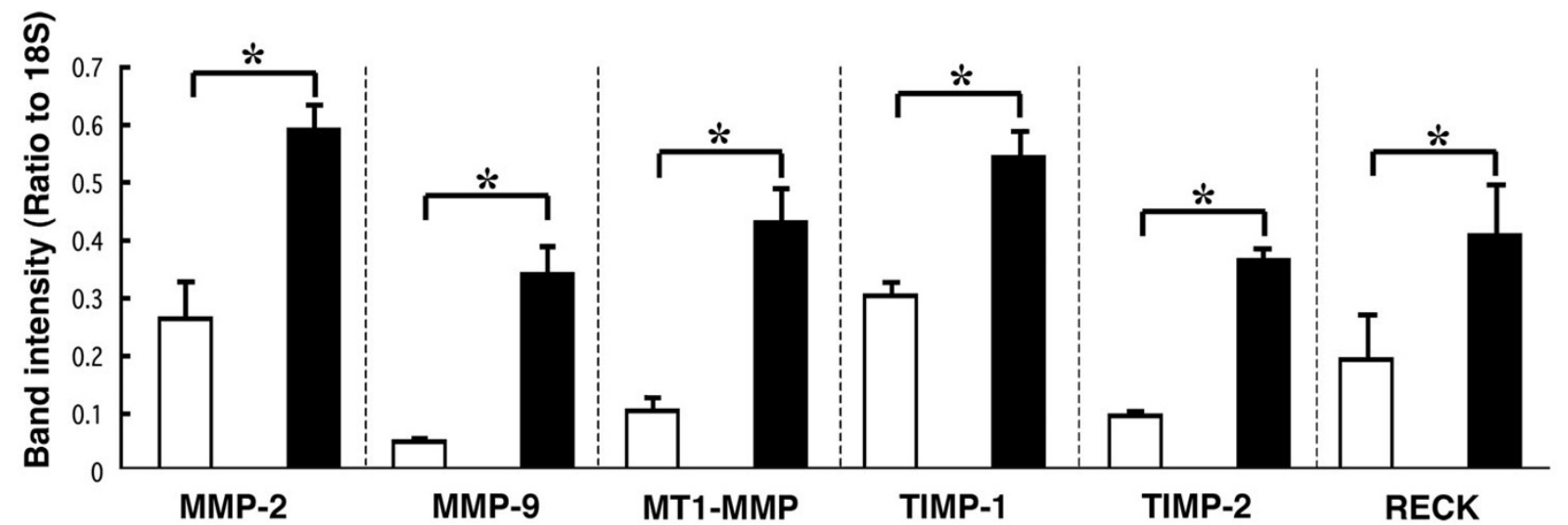

Figure 5

Relative mRNA levels of MMPs, endogenous MMPs inhibitors, and RECK in muscle from normal and CXMD, dogs. The mRNA levels of MMP-2, MMP-9, MTI-MMP, TIMP-I, TIMP-2, and RECK were examined by semi-quantitative RTPCR. The control dogs (open bar, $n=3$ ), CXMD (closed bar, $n=3$ ). Bar: mean \pm SEM; $* P<0.0 I$.

formed pathological analyses. KY participated in the maintenance of the dogs and necropsy. KY participated in the molecular analyses. ST participated in the design and coordination of the study. SI participated in the planning and coordination of the study. All authors read and approved the final manuscript.

\section{Acknowledgements}

We thank Naoko Yugeta, D.V.M. (School of Veterinary Medicine, Azabu University) for advising on the healthy care of dogs and also thank Hideki Kita, Shin'ichi Ichikawa, Yumiko Yahata, and Kazue Kinoshita (JAC, Inc., Tokyo) for maintaining the dogs.

This study was supported by the Research Grant for Nervous and Mental Disorders from the Ministry of Health, Labour and Welfare (I7A-10), Health Sciences Research Grants for Research on Psychiatric and Neurological Diseases and Mental Health (HI8-kokoro-0 19), the Human Genome and Gene Therapy (HI6-genome-003) from the Ministry of Health, Labor and Welfare of Japan, the Grants-in-Aid for Scientific Research from the Ministry of Education, Culture, Sports, Science and Technology of Japan.

\section{References}

I. Hoffman EP, Brown RH Jr., Kunkel LM: Dystrophin: the protein product of the Duchenne muscular dystrophy locus. Cell 1987, 5 I(6):919-928.

2. Ohlendieck K, Campbell KP: Dystrophin-associated proteins are greatly reduced in skeletal muscle from $\mathbf{m d x}$ mice. J Cell Biol 1991, I I5(6): 1685-1694.

3. Ohlendieck K, Matsumura K, lonasescu VV, Towbin JA, Bosch EP, Weinstein SL, Sernett SW, Campbell KP: Duchenne muscular dystrophy: deficiency of dystrophin-associated proteins in the sarcolemma. Neurology 1993, 43(4):795-800.

4. Blau HM, Webster C, Pavlath GK: Defective myoblasts identified in Duchenne muscular dystrophy. Proc Natl Acad Sci U S A 1983, 80( (15):4856-4860.

5. Schenk S, Quaranta V: Tales from the crypt[ic] sites of the extracellular matrix. Trends Cell Biol 2003, I3(7):366-375.

6. Sans JR: The Extracellular Matrix. In Myology Volume Volume I. 3rd edition. Edited by: Engel A FAC. New York , McGraw-Hill; 2004:47I-478.
7. Carmeli E, Moas M, Reznick AZ, Coleman R: Matrix metalloproteinases and skeletal muscle: a brief review. Muscle Nerve 2004, 29(2): $191-197$.

8. McCawley LJ, Matrisian LM: Matrix metalloproteinases: they're not just for matrix anymore! Curr Opin Cell Biol 200I, 13(5):534-540.

9. Balcerzak D, Querengesser L, Dixon WT, Baracos VE: Coordinate expression of matrix-degrading proteinases and their activators and inhibitors in bovine skeletal muscle. J Anim Sci 200I, 79(I):94-107.

10. Nagase $\mathrm{H}$, Woessner JF Jr:: Matrix metalloproteinases. J Biol Chem 1999, 274(31):2149|-21494.

II. Gomis-Ruth FX: Structural aspects of the metzincin clan of metalloendopeptidases. Mol Biotechnol 2003, 24(2): 157-202.

12. Sato H, Takino T, Kinoshita T, Imai K, Okada Y, Stetler Stevenson WG, Seiki M: Cell surface binding and activation of gelatinase $A$ induced by expression of membrane-type- I-matrix metalloproteinase (MTI-MMP). FEBS Lett 1996, 385(3):238-240.

13. Strongin AY, Collier I, Bannikov G, Marmer BL, Grant GA, Goldberg $\mathrm{GI}$ : Mechanism of cell surface activation of 72-kDa type IV collagenase. Isolation of the activated form of the membrane metalloprotease. J Biol Chem 1995, 270( (10):533 I-5338.

14. Kinoshita T, Sato H, Okada A, Ohuchi E, Imai K, Okada Y, Seiki M: TIMP-2 promotes activation of progelatinase $A$ by membrane-type I matrix metalloproteinase immobilized on agarose beads. J Biol Chem 1998, 273(26):16098-16103.

15. Butler GS, Butler MJ, Atkinson SJ, Will H, Tamura T, Schade van Westrum S, Crabbe T, Clements J, d'Ortho MP, Murphy G: The TIMP2 membrane type I metalloproteinase "receptor" regulates the concentration and efficient activation of progelatinase A. A kinetic study. J Biol Chem 1998, 273(2):87I-880.

16. Atkinson SJ, Crabbe T, Cowell S, Ward RV, Butler MJ, Sato H, Seiki $M$, Reynolds ]J, Murphy G: Intermolecular autolytic cleavage can contribute to the activation of progelatinase $A$ by cell membranes. J Biol Chem 1995, 270(5 I):30479-30485.

17. Oh J, Takahashi R, Kondo S, Mizoguchi A, Adachi E, Sasahara RM, Nishimura S, Imamura Y, Kitayama H, Alexander DB, Ide C, Horan TP, Arakawa T, Yoshida H, Nishikawa S, Itoh Y, Seiki M, Itohara S, Takahashi C, Noda M: The membrane-anchored MMP inhibitor RECK is a key regulator of extracellular matrix integrity and angiogenesis. Cell 200I, 107(6):789-800.

18. Sasahara RM, Brochado SM, Takahashi C, Oh J, Maria-Engler SS, Granjeiro JM, Noda M, Sogayar MC: Transcriptional control of the RECK metastasis/angiogenesis suppressor gene. Cancer Detect Prev 2002, 26(6):435-443.

19. Takahashi C, Sheng Z, Horan TP, Kitayama H, Maki M, Hitomi K, Kitaura Y, Takai S, Sasahara RM, Horimoto A, Ikawa Y, Ratzkin B], Arakawa T, Noda M: Regulation of matrix metalloproteinase-9 
and inhibition of tumor invasion by the membrane-anchored glycoprotein RECK. Proc Natl Acad Sci U S A 1998, 95(22): | $322|-| 3226$.

20. Birkedal-Hansen H, Moore WG, Bodden MK, Windsor LJ, BirkedalHansen B, DeCarlo A, Engler JA: Matrix metalloproteinases: a review. Crit Rev Oral Biol Med 1993, 4(2): 197-250.

21. Gueders MM, Foidart JM, Noel A, Cataldo DD: Matrix metalloproteinases (MMPs) and tissue inhibitors of MMPs in the respiratory tract: potential implications in asthma and other lung diseases. Eur J Pharmacol 2006, 533( I-3):| 33-| 44.

22. DeGraba TJ: Immunogenetic susceptibility of atherosclerotic stroke: implications on current and future treatment of vascular inflammation. Stroke 2004, 35( I I SuppI I):27I 2-27 I9.

23. Zhao BQ, Wang S, Kim HY, Storrie H, Rosen BR, Mooney DJ, Wang $\mathrm{X}$, Lo EH: Role of matrix metalloproteinases in delayed cortical responses after stroke. Nat Med 2006, I 2(4):44I-445.

24. Vihinen $P$, Kahari VM: Matrix metalloproteinases in cancer: prognostic markers and therapeutic targets. Int J Cancer 2002, 99(2): I57-166.

25. Spinale FG, Coker ML, Heung LJ, Bond BR, Gunasinghe HR, Etoh T, Goldberg AT, Zellner JL, Crumbley AJ: A matrix metalloproteinase induction/activation system exists in the human left ventricular myocardium and is upregulated in heart failure. Circulation 2000, 102(16): 1944-1949.

26. Burrage PS, Mix KS, Brinckerhoff CE: Matrix metalloproteinases: role in arthritis. Front Biosci 2006, I I:529-543.

27. Overall CM, Kleifeld O: Towards third generation matrix metalloproteinase inhibitors for cancer therapy. Br J Cancer 2006, 94(7):941-946.

28. Aimes RT, Quigley JP: Matrix metalloproteinase-2 is an interstitial collagenase. Inhibitor-free enzyme catalyzes the cleavage of collagen fibrils and soluble native type I collagen generating the specific 3/4- and I/4-length fragments. J Biol Chem 1995, 270(I i):5872-5876.

29. Birkedal-Hansen H: Proteolytic remodeling of extracellular matrix. Curr Opin Cell Biol 1995, 7(5):728-735.

30. Schoser BG, Blottner D, Stuerenburg HJ: Matrix metalloproteinases in inflammatory myopathies: enhanced immunoreactivity near atrophic myofibers. Acta Neurol Scand 2002, I 05(4):309-3।3.

31. Choi YC, Dalakas MC: Expression of matrix metalloproteinases in the muscle of patients with inflammatory myopathies. Neurology 2000, 54(I):65-7I.

32. Kieseier BC, Schneider C, Clements JM, Gearing AJ, Gold R, Toyka $\mathrm{KV}$, Hartung HP: Expression of specific matrix metalloproteinases in inflammatory myopathies. Brain 200I, I 24(Pt 2):34|-35I.

33. von Moers A, Zwirner A, Reinhold A, Bruckmann O, van Landeghem F, Stoltenburg-Didinger G, Schuppan D, Herbst H, Schuelke M: Increased mRNA expression of tissue inhibitors of metalloproteinase-I and -2 in Duchenne muscular dystrophy. Acta Neuropathol (Berl) 2005, I 09(3):285-293.

34. Kherif S, Lafuma C, Dehaupas M, Lachkar S, Fournier JG, VerdiereSahuque M, Fardeau M, Alameddine HS: Expression of matrix metalloproteinases 2 and 9 in regenerating skeletal muscle: a study in experimentally injured and mdx muscles. Dev Biol 1999, 205(I): I58-170.

35. Nakamura A, Yoshida K, Ueda H, Takeda S, Ikeda S: Up-regulation of mitogen activated protein kinases in $\mathrm{mdx}$ skeletal muscle following chronic treadmill exercise. Biochim Biophys Acta 2005, I 740(3):326-33|.

36. Yamada H, Saito F, Fukuta-Ohi H, Zhong D, Hase A, Arai K, Okuyama A, Maekawa R, Shimizu T, Matsumura K: Processing of beta-dystroglycan by matrix metalloproteinase disrupts the link between the extracellular matrix and cell membrane via the dystroglycan complex. Hum Mol Genet 200I, I O(I5): I563-I569.

37. Matsumura K, Zhong D, Saito F, Arai K, Adachi K, Kawai H, Higuchi I, Nishino I, Shimizu T: Proteolysis of beta-dystroglycan in muscular diseases. Neuromuscul Disord 2005, I 5(5):336-34I.

38. Zhong D, Saito F, Saito Y, Nakamura A, Shimizu T, Matsumura K Characterization of the protease activity that cleaves the extracellular domain of beta-dystroglycan. Biochem Biophys Res Commun 2006, 345(2):867-87I.

39. Shimatsu $Y$, Yoshimura M, Yuasa K, Urasawa N, Tomohiro M, Nakura M, Tanigawa M, Nakamura A, Takeda S: Major clinical and his- topathological characteristics of canine $\mathbf{X}$-linked muscular dystrophy in Japan, CXMDJ. Acta Myol 2005, 24(2): I 45-I54.

40. Sharp NJ, Kornegay JN, Van Camp SD, Herbstreith MH, Secore SL, Kettle S, Hung WY, Constantinou CD, Dykstra MJ, Roses AD, et al.: An error in dystrophin mRNA processing in golden retriever muscular dystrophy, an animal homologue of Duchenne muscular dystrophy. Genomics 1992, I3(I): | I5-I2I.

4I. Shimatsu Y, Katagiri K, Furuta T, Nakura M, Tanioka Y, Yuasa K, Tomohiro M, Kornegay JN, Nonaka I, Takeda S: Canine X-linked muscular dystrophy in Japan (CXMDJ). Exp Anim 2003 52(2):93-97.

42. Fujiwara A, Shibata E, Terashima $H$, Shishido A, Nishiki J, Yoshida $K$ Miyauchi K, Madachi A, Matsuura N: Evaluation of Matrix Metalloproteinase-2 (MMP-2) Activity with Film in situ Zymography for Improved Cytological Diagnosis of Breast Tumors. Breast Cancer 2006, I3(3):272-278.

43. Shiraga M, Yano S, Yamamoto A, Ogawa H, Goto H, Miki T, Miki K, Zhang $\mathrm{H}$, Sone S: Organ heterogeneity of host-derived matrix metalloproteinase expression and its involvement in multiple-organ metastasis by lung cancer cell lines. Cancer Res 2002 , 62(20):5967-5973

44. Kaneyoshi T, Nakatsukasa H, Higashi T, Fujiwara K, Naito I, Nouso K, Kariyama K, Kobayashi Y, Uemura M, Nakamura SI, Iwasaki Y, Tsuji $\mathrm{T}$ : Actual invasive potential of human hepatocellular carcinoma revealed by in situ gelatin zymography. Clin Cancer Res 200 I, 7( I 2):4027-4032.

45. Nakada M, Nakamura $H$, Ikeda E, Fujimoto $N$, Yamashita J, Sato $H$, Seiki M, Okada $Y$ : Expression and tissue localization of membrane-type I, 2, and 3 matrix metalloproteinases in human astrocytic tumors. Am J Pathol 1999, I 54(2):4I 7-428.

46. Ohashi K, Nemoto T, Nakamura K, Nemori R: Increased expression of matrix metalloproteinase 7 and 9 and membrane type I-matrix metalloproteinase in esophageal squamous cell carcinomas. Cancer 2000, 88( I 0):2201-2209.

47. Kaji M, Moriyama S, Sasaki H, Saitoh Y, Kiriyama M, Fukai I, Yamakawa Y, Mitsui A, Toyama T, Nemori R, Fujii Y: Gelatinolytic activity of matrix metalloproteinase in lung cancer studied using film in situ zymography stamp method. Lung Cancer 2003, 39(2): $125-130$.

48. Nakano Y, Niida S, Dote K, Takenaka S, Hirao H, Miura F, Ishida M, Shingu T, Sueda T, Yoshizumi M, Chayama K: Matrix metalloproteinase-9 contributes to human atrial remodeling during atrial fibrillation. J Am Coll Cardiol 2004, 43(5):8I8-825.

49. Frederiks WM, Mook OR: Metabolic mapping of proteinase activity with emphasis on in situ zymography of gelatinases: review and protocols. J Histochem Cytochem 2004, 52(6):7 I I-722.

50. Corbi AL, Kishimoto TK, Miller LJ, Springer TA: The human leukocyte adhesion glycoprotein Mac-I (complement receptor type 3, CDI Ib) alpha subunit. Cloning, primary structure, and relation to the integrins, von Willebrand factor and factor B. I Biol Chem 1988, 263(25): I2403-124II.

5I. Davis CE, Harris JB, Nicholson LV: Myosin isoform transitions and physiological properties of regenerated and re-innervated soleus muscles of the rat. Neuromuscul Disord 1991, I(6):4| |-42|

52. Birkedal-Hansen H, Taylor RE: Detergent-activation of latent collagenase and resolution of its component molecules. Biochem Biophys Res Commun 1982, I 07(4): 1 I73-1 I 78.

53. Guerin CW, Holland PC: Synthesis and secretion of matrixdegrading metalloproteases by human skeletal muscle satellite cells. Dev Dyn 1995, 202(I):91-99.

54. Daimon E, Wada Y: Role of neutrophils in matrix metalloproteinase activity in the preimplantation mouse uterus. Biol Reprod 2005, 73(I):|63-17|.

55. Gilbert SJ, Wotton PR, Tarlton JF, Duance VC, Bailey AJ: Increased expression of promatrix metalloproteinase-9 and neutrophil elastase in canine dilated cardiomyopathy. Cardiovasc Res 1997. 34(2):377-383.

56. Ohtake Y, Tojo H, Seiki M: Multifunctional roles of MT I-MMP in myofiber formation and morphostatic maintenance of skeletal muscle. J Cell Sci 2006, I I 9(Pt I 8):3822-3832.

57. Echizenya M, Kondo S, Takahashi R, Oh J, Kawashima S, Kitayama H, Takahashi C, Noda M: The membrane-anchored MMP-regulator RECK is a target of myogenic regulatory factors. Oncogene 2005, 24(38):5850-5857. 


\section{Pre-publication history}

The pre-publication history for this paper can be accessed here:

http://www.biomedcentral.com/1471-2474/8/54/prepub

Publish with Bio Med Central and every scientist can read your work free of charge

"BioMed Central will be the most significant development for disseminating the results of biomedical research in our lifetime. " Sir Paul Nurse, Cancer Research UK

Your research papers will be:

- available free of charge to the entire biomedical community

- peer reviewed and published immediately upon acceptance

- cited in PubMed and archived on PubMed Central

- yours - you keep the copyright 